\title{
Evidenciação da remuneração estratégica em empresas do setor elétrico de 2003 a 2007
}

\author{
Disclosure of strategic compensation in companies of the electric sector of 2003 to 2007
}

Rejane de Mello Cardozo ${ }^{[a]}$, Cristiano do Nascimento ${ }^{[b]}$, Valdirene Gasparetto ${ }^{[c]}$

[a] Bacharel em Contabilidade pela Universidade Federal de Santa Catarina (UFSC), Florianópolis, SC - Brasil, e-mail: relaguna2000@yahoo.com.br

[b] Mestre em Contabilidade pela Universidade Federal do Paraná (UFPR), Curitiba, PR - Brasil, e-mail: cristiano.do.nascimento@live.com

[c] Doutora em Engenharia de Produção pela Universidade Federal de Santa Catarina (UFSC), professora do Departamento de Ciências Contábeis da Universidade Federal de Santa Catarina (UFSC), Florianóplois, SC - Brasil, e-mail: valdirene@cse.ufsc.br

\section{Resumo}

Este estudo tem como objetivo principal investigar as formas de remuneração estratégica evidenciadas pelas empresas do setor de energia elétrica no Brasil. A amostra da pesquisa é composta por 52 empresas que possuem ações negociadas na BM\&FBOVESPA (Bolsa de Valores, Mercadorias e Futuros), envolvendo o período de 2003 a 2007. A metodologia empregada tem caráter descritivo devido ao fato de investigar informações contidas nos relatórios de administração. Aplica-se abordagem qualitativa e quantitativa para fins de análise. Dentre os resultados encontrados, constatou-se que, de 2003 até 2007, aumentou o número de empresas que passaram a evidenciar remuneração estratégica, de 46\% das empresas analisadas em 2003 para 65\% em 2007; e que $21 \%$ evidenciaram, simultaneamente, no relatório da administração, a destinação de remuneração variável e salário indireto, de 2003 até 2007. As práticas de remuneração estratégica buscam valorizar as competências dos colaboradores, com vistas a mantê-los comprometidos com o bom desempenho de suas atividades, contudo existem empresas do setor elétrico que ainda não visualizaram a importância da divulgação das práticas referentes às formas de remuneração dos colaboradores.

Palavras-chave: Remuneração estratégica. Evidenciação. Setor elétrico.

\section{Abstract}

This study aims at investigating the forms of compensation evidenced by strategic at companies in the electricity sector in Brazil. The sample consists of 52 companies listed in BM\&FBOVESPA (São Paulo Stock Exchange) concerning the period from 2003 to 2007. This is a descriptive study, using qualitative and quantitative approach. Among the study's findings, stands out: of 2003 to 2007, increased the number of companies now highlight strategic remuneration with 46\% of companies surveyed in 2003 to 65\% in 2007; and 21\% released, simultaneously, in the 
management's report on the allocation of performance-dependent reward and indirect wage from 2003 to 2007. The strategic compensation practices seek to value the skills of employees, in order to keep them committed to the good performance of its activities, but there are electric sector companies that have not yet viewed the importance of disclosure practices regarding forms of remuneration of the employee.

Keywords: Strategic compensation. Disclosure. Electricity sector.

\section{Introdução}

As empresas do setor elétrico brasileiro, que têm como suporte a colaboração de seu pessoal, encontram-se em meio ao desafio de transformar a visão tradicional da remuneração em fator de vantagem competitiva. Em um ambiente competitivo, o fator humano destaca-se pela capacidade de gerar resultados. Sob esta perspectiva, ressalta-se a necessidade de um exame quanto às formas de remuneração de pessoal.

0 setor de energia elétrica brasileiro, sob a perspectiva de gestão de pessoal, também busca se ajustar às transformações no ambiente empresarial. Neste sentido, em meio às novas tendências que buscam ampliar a competitividade a partir da remuneração, as empresas buscam complementar a remuneração fixa com outras formas de remuneração, que auxiliem na motivação e maior envolvimento dos colaboradores no alcance dos objetivos da empresa, como argumentam Wood Junior e Picarelli Filho (1996, p. 32):

as formas tradicionais de gestão só servem para contextos tradicionais de negócios, que estão em extinção. A empresa típica do início do século cresceu e adaptou-se a suas novas condições, estruturando-se em grandes corporações burocráticas para atender à expansão internacional da demanda. De forma semelhante, a forma burocrática de organização parece estar superada, em um mundo em que cada vez mais é a agilidade e a adaptabilidade, e não a estruturação complexa, que determinam a sobrevivência das organizações.

0 setor de energia elétrica tem passado por mudanças a partir de 1995, ano em que houve a reestruturação de seus segmentos. A privatização das empresas permitiu que um grande número de novos agentes se incorporasse ao setor, abrindo assim o mercado à concorrência privada nacional e estrangeira. As empresas que fazem parte do setor têm feito grandes esforços para melhorar sua competitividade.
Neste sentido, surgiu o interesse em verificar quais as formas de remuneração estratégica adotadas no setor de energia elétrica.

De acordo com Clasen (2000), quando a organização considera o potencial do ser humano como diferencial competitivo, reconhece que introduzir novas formas de remuneração pode auxiliar no seu aperfeiçoamento contínuo. Nesse sentido, Possani (1996 apud CLASEN, 2000) destaca que a nova forma de remuneração caracteriza-se pela responsabilidade por resultados e pela recompensa do alcance de metas de desempenho. Diante do exposto, emerge a seguinte questão-problema: quais as formas de remuneração estratégica adotadas pelas empresas brasileiras de energia elétrica que têm ações negociadas na BM\&FBOVESPA (Bolsa de Valores, Mercadorias e Futuros)?

O objetivo principal desta pesquisa é identificar a evidenciação de informações sobre as formas de remuneração estratégica das empresas brasileiras de energia elétrica que têm ações negociadas na BM\&FBOVESPA. De forma complementar, busca-se conhecer a evolução na adesão de formas de remuneração estratégica, ao longo do período pesquisado, pelas empresas envolvidas na pesquisa. Para isto, faz-se uso das informações contidas nos relatórios de administração das empresas pertencentes ao setor, listadas na BM\&FBOVESPA.

A adoção da remuneração estratégica desponta como uma fonte de vantagem competitiva, pois estimula o desenvolvimento dos recursos internos. Neste contexto, destaca-se a amplitude da pesquisa, na qual se executa um levantamento dos diferentes tipos de remuneração adotados em 52 empresas do setor elétrico brasileiro com ações negociadas na BM\&FBOVESPA. Diante do exposto, a partir da evidenciação de informações sobre a remuneração dispostas nos relatórios da administração das empresas, executa-se este estudo para identificar as formas de remuneração estratégica, cujo conteúdo revelado tende a gerar interesse dos profissionais que atuam 
no setor, assim como o interesse de investidores acerca das políticas de remuneração de pessoal praticadas pelas empresas do setor elétrico.

Para atender o objetivo de pesquisa, $\mathrm{o}$ artigo foi estruturado em quatro seções, incluindo esta primeira, em que se apresenta a introdução. A segunda seção mostra o referencial teórico do trabalho; na terceira são apresentados os procedimentos metodológicos do trabalho. A quarta seção mostra os resultados da pesquisa, e na seção 5 traz-se as considerações finais do trabalho. Após são apresentadas as referências consultadas.

\section{Referencial teórico}

Nesta seção discute-se os temas que sustentam a pesquisa realizada, iniciando pela evidenciação contábil, e após apresentando a remuneração estratégica, mostrando sua importância para a empresa e para os colaboradores.

\section{A evidenciação contábil}

A contabilidade é definida como um sistema de informação e mensuração de eventos que afetam a tomada de decisão, cujo propósito é auxiliar a organização a atingir seus objetivos (FIGUEIREDO; CAGGIANO, 1997). Neste sentido, Hendriksen e Van Breda (1999), Lunkes (2007) e Iudícibus e Marion (1999) argumentam que o objetivo da contabilidade consiste em fornecer informações estruturadas de natureza econômica, financeira e, subsidiariamente, física, de produtividade e social, aos usuários internos e externos à entidade.

Conforme Iudícibus e Marion (1999), a evidenciação contábil é apresentada sob a forma de relatórios, dentre eles os obrigatórios, que são exigidos por lei, conhecidos como demonstrações financeiras, e os não obrigatórios, utilizados na administração da entidade. Lunkes (2007, p. 48) afirma que dentre as características da informação gerencial "pode-se destacar: a precisão, relevância, oportunidade, exatidão, compreensão, uniformidade e abrangência".

Dentre as formas de realizar a evidenciação contábil, destaca-se a importância da divulgação do relatório da administração como instrumento que reúne informações relevantes na tomada de decisão, pois os relatórios da administração podem conter informações importantes, que contribuem na tomada de decisão dos usuários, não só ao fornecer projeções e operações previstas para o futuro, mas também ao fazer análises do passado, e por indicar tendências futuras (IUDÍCIBUS; MARTINS; GELBCKE, 2007).

As empresas, ao final do exercício, divulgam o relatório anual aos acionistas, por vezes chamado de relatório da administração, que poderá incluir uma carta da administração da empresa resumindo as atividades do ano anterior e expressando considerações e perspectivas para o ano seguinte. Neste contexto, nota-se a importância das informações em termos qualitativos em conjunto com as informações quantitativas.

As entidades devem fornecer informações quantitativas e qualitativas que atendam às necessidades dos usuários das informações contábeis. Iudícibus (2004, p. 125) entende que a informação qualitativa ou não quantitativa é muito mais difícil de ser avalia$\mathrm{da}$, pois ela envolve julgamentos subjetivos e acrescenta, "normalmente, a relevância de alguns itens qualitativos emerge de seu relacionamento direto com os quantitativos".

De acordo com Iudícibus, Martins e Gelbcke (2007), as informações quantitativas, quando aplicadas a uma entidade, devem possibilitar ao usuário avaliar a situação e as tendências desta, com menor grau de dificuldade possível. Com relação às características da informação, sejam elas qualitativas ou quantitativas, todas as informações disponibilizadas ao usuário devem ser, ao mesmo tempo, adequadas, justas e plenas, pelo menos no que se refere ao assunto que está sendo evidenciado (IUDÍCIBUS, 2004).

Conforme Hendriksen e Van Breda (1999, p. 95), as características qualitativas compreendem "as propriedades da informação que são necessárias para torná-la útil". Conforme Iudícibus e Marion (1999), a qualidade da informação contábil pode ser verificada por sua utilidade que equivale a benefício comparado ao seu custo, devendo possuir características como: compreensibilidade, relevância, confiabilidade e comparabilidade.

\section{Remuneração estratégica}

Em meio às novas tendências que buscam ampliar a competitividade a partir da remuneração, a tendência nas empresas é complementar a remuneração fixa com outras formas de remuneração, que 
auxiliem na motivação e maior envolvimento dos colaboradores no alcance dos objetivos da empresa. Diante desta perspectiva, as empresas tendem a adotar sistemas de remuneração estratégica, que consistem nas várias formas de remuneração utilizadas em conjunto com a forma tradicional (salários fixos, baseados em plano de cargos e salários) como, por exemplo: salário indireto, remuneração por habilidades ou por competências, plano privado de aposentadoria, remuneração variável (participação nos lucros ou resultados), participação acionária e alternativas criativas ou formas especiais de recompensa (WOOD JUNIOR; PICARELLI FILHO, 1996).

A remuneração estratégica está vinculada à "nova realidade das organizações que atuam no mercado globalizado e competitivo" (WOOD JUNIOR; PICARELLI FILHO, 1996, p. 40). A princípio o vínculo acontece porque a empresa considera todo o contexto organizacional e, principalmente, o que a empresa deseja ser no futuro. Em seguida são consideradas as atividades e responsabilidades, e os indivíduos passam a ser remunerados de acordo com sua contribuição para o sucesso do negócio. Além disso, são considerados aspectos como conhecimentos, habilidades, competências, desempenho, resultados e evolução de carreira (WOOD JUNIOR; PICARELLI FILHO, 1996).

Define-se remuneração estratégica como um sistema de práticas de remuneração que, quando aplicado à realidade de uma organização, deverá estar alinhado com seus objetivos estratégicos e servirá de reforço e incentivo aos esforços dos seus profissionais (CARDOSO, 1999). Segundo Miranda (2005):

por muito tempo, o salário fixo pago no final de cada mês foi a forma mais comum e eficiente de remunerar o trabalho dos empregados. Como muitas práticas do ambiente empresarial, essa realidade mudou radicalmente nos últimos anos. Hoje para competir em um mercado onde as margens de lucro estão cada vez mais estreitas e a motivação das equipes é um desafio permanente, a remuneração estratégica vem ganhando cada vez mais espaço, consolidando-se como uma importante ferramenta de gestão.

A remuneração, por vezes, assume papel decisivo no desempenho das atividades, pois serve como ferramenta de motivação para os colaboradores e também como forma de mantê-los comprometidos com os objetivos da empresa. Neste sentido, ressalta-se a importância da remuneração estratégica para a empresa e para o colaborador.

Importância da remuneração

estratégica para a empresa

A concorrência entre as empresas gera a necessidade de adaptação a mudanças e inovações. Para atingir esse objetivo, nota-se a busca constante do comprometimento dos colaboradores nas empresas. De acordo com Clasen (2000), quando a organização considera o potencial humano como diferencial competitivo, reconhece que ao introduzir novas formas de remuneração estas passam a ser um auxílio no aperfeiçoamento contínuo da empresa.

Como esclarecem Reis Neto e Marques (2004), a visão usual de remuneração, antes considerada um custo, passa a ser considerada um fator de aperfeiçoamento e impulsionador do processo de melhoria e aumento da competitividade. Portanto, a remuneração estratégica é de grande importância no incentivo aos colaboradores em participar ativamente das mudanças.

A remuneração estratégica é formada por vários componentes. Dentre os componentes destaca-se o salário indireto, que compreende benefícios e vantagens e que faz parte da remuneração do pessoal (CHIAVENATO, 2004). Para a empresa existe vantagem na adoção de salário indireto, conforme comentam Wood Junior e Picarelli Filho (1996): a empresa que assume esta postura de conceder benefícios possui maiores possibilidades de atração e retenção de mão de obra, principalmente quando o negócio impõe alto nível de capacitação profissional.

Em síntese, um sistema de remuneração estratégica consiste numa forma de mudança interna na condução dos negócios, fato que resulta na composição de um diferencial competitivo da empresa frente aos concorrentes.

Importância da remuneração estratégica para o colaborador

Os colaboradores, nas organizações, destacam-se em cumprir o papel de intermediários entre a empresa e o cliente. Como procuram adaptar-se às novas necessidades do mercado, também esperam ser recompensados. Uma das formas de recompensa 
consiste na remuneração, que é considerada como meio de incentivar os colaboradores a ter um maior envolvimento nas atividades da empresa.

Conforme Chiavenato (2004), para ambos, empresa e colaborador, sentirem-se satisfeitos, existe a necessidade de uma troca, em que o colaborador cede seu talento, suas habilidades, sua dedicação, inteligência e criatividade, em contrapartida, a empresa põe à disposição seus recursos, com o intuito de alcançarem seus objetivos. Desta forma, as pessoas dedicam-se ao trabalho desde que a recompensa seja significativa comparada ao esforço e dedicação do colaborador.

É importante que as pessoas se sintam reconhecidas pela empresa, conforme Hipólito (2002) declara: ao não reconhecer os colaboradores que vão além dos limites estabelecidos pelo cargo, resulta certamente em frustração e descontentamento, e isto pode interferir no interesse do colaborador querer ficar na empresa ou sair em busca de novas oportunidades profissionais.

A empresa pode conceder por meio da remuneração estratégica (salário indireto) benefícios e certas regalias a título de pagamento adicional dos salários, à totalidade ou a parte de seus funcionários. Os benefícios e serviços sociais incluem uma variedade de facilidades e vantagens oferecidas pela organização, como assistência médica e hospitalar, seguro de vida, alimentação subsidiada, transporte, entre outros (CHIAVENATO, 2004).

\section{Procecimentos metodológicos}

0 presente trabalho consiste em uma pesquisa aplicada, tendo, quanto aos objetivos, caráter descritivo. Conforme Andrade (2002 apud RAUPP; BEUREN, 2006, p. 81), "a pesquisa descritiva preocupa-se em observar os fatos, registrá-los, analisá-los e interpretá-los, e o pesquisador não interfere neles".

Quanto à estratégia de abordagem, foi realizado levantamento documental, proveniente de fontes secundárias, sendo estas os relatórios de administração das 52 empresas do setor de energia elétrica brasileiras que negociam ações na BM\&FBOVESPA. Conforme Cervo, Bervian e Silva (2007, p. 62), as informações obtidas em documentos de fontes secundárias contribuem para o desenvolvimento do trabalho, pois na pesquisa documental "são investigados documentos com o propósito de se poder descrever e comparar usos e costumes, tendências, diferenças e outras características.

A abordagem desta pesquisa apresenta caráter qualitativo e quantitativo. Richardson (1999) expõe que a abordagem qualitativa não emprega um instrumento estatístico como base do processo de análise do problema, fato que, segundo o referido autor, a utilização da pesquisa quantitativa em estudos de levantamento consiste numa tentativa de entender, utilizando-se de uma amostra, o comportamento de uma população. De acordo com Triviños (2006, p. 111), "a análise qualitativa pode ter apoio quantitativo, mas geralmente se omite a análise estatística ou o seu emprego não é sofisticado". Este estudo também utiliza-se de abordagem quantitativa para fins de análise, porém sem perder o caráter qualitativo quando transformado em dados quantificáveis.

A pesquisa realizada diferencia o conjunto de empresas que evidenciam a adoção de políticas de remuneração estratégica das que não o fazem, ao longo do período entre 2003 e 2007, sendo o relatório da administração a principal fonte de informações para a execução deste estudo. A pesquisa abrange 52 empresas brasileiras do setor de energia elétrica que têm ações negociadas na BM\&FBOVESPA, a partir dos relatórios publicados na homepage até o dia 09 de abril de 2008. Ressalta-se o fato de haver obrigatoriedade legal em evidenciar nas demonstrações contábeis as informações que tratam de formas de remuneração estratégica aos colaboradores.

Em relação aos termos pesquisados nos relatórios da administração, buscou-se por: remuneração estratégica; remuneração funcional; salário indireto; remuneração por habilidades ou por competências; plano privado de aposentadoria; remuneração variável (participação nos lucros e ou resultados); e participação acionária e alternativas criativas ou formas especiais de recompensa. Após a seleção da amostra, iniciou-se a busca de informações relativas à remuneração estratégica nos relatórios da administração com o intuito de atender o objetivo principal desta pesquisa.

\section{Resultados da pesquisa}

A pesquisa sobre a evidenciação de remuneração estratégica constatou que as empresas divulgam apenas salário indireto e remuneração variável em seus relatórios. Com o objetivo de identificar e coletar dados para compor a base de dados e posterior 
desenvolvimento deste estudo, estipulou-se a expressão SI para salário indireto, e RV para remuneração variável.

O Quadro 1 demonstra as formas de remuneração estratégica adotadas pelas empresas que atuam no setor elétrico brasileiro.

Conforme Quadro 1, ao longo de todo o período pesquisado, 11 empresas, ou seja, $21 \%$, evidenciaram, simultaneamente, no relatório da administração, a destinação de remuneração variável e salário indireto, os quais constituem as formas de remuneração estratégica destinada a seus colaboradores. Ainda conforme o Quadro 1, ao longo do período considerado na análise, $73 \%$ das empresas mostraram a adoção da remuneração estratégica. Destaca-se que 15,4\% das empresas utilizaram-se da remuneração estratégica em apenas um período. Por fim, $27 \%$ das empresas não evidenciaram qualquer forma de remuneração estratégica no período analisado, especialmente no segmento de participações, que somente em 2007 destina salário indireto e remuneração variável.

Quadro 1 - Demonstrativo das empresas que praticam alguma forma de remuneração estratégica

(continua)

\begin{tabular}{|c|c|c|c|c|c|c|c|c|c|c|}
\hline \multirow[t]{3}{*}{ Empresa } & \multicolumn{10}{|c|}{ Remuneração estratégica } \\
\hline & \multicolumn{2}{|c|}{2003} & \multicolumn{2}{|c|}{2004} & \multicolumn{2}{|c|}{2005} & \multicolumn{2}{|c|}{2006} & \multicolumn{2}{|c|}{2007} \\
\hline & $\mathrm{SI}^{*}$ & $\mathrm{RV}^{* *}$ & $\mathrm{SI}^{*}$ & $\mathrm{RV}^{* *}$ & $\mathrm{SI}^{*}$ & $\mathrm{RV}^{* *}$ & $\mathrm{SI}{ }^{*}$ & $\mathrm{RV}^{* *}$ & $\mathrm{SI} *$ & $\mathrm{RV}$ ** \\
\hline \multicolumn{11}{|l|}{ Atividade geração } \\
\hline AES TIETÊ & & $x$ & $x$ & $\mathrm{x}$ & $\mathrm{x}$ & $x$ & $x$ & $\mathrm{x}$ & $x$ & $\mathrm{x}$ \\
\hline \multicolumn{11}{|l|}{ BAESA } \\
\hline CPFL GERAÇÃO & $x$ & $x$ & $x$ & $x$ & $x$ & $x$ & $x$ & $x$ & $x$ & $x$ \\
\hline DUKE GER PARANAP & $x$ & $x$ & $x$ & $\mathrm{x}$ & $x$ & $\mathrm{x}$ & $\mathrm{x}$ & $x$ & $x$ & $\mathrm{x}$ \\
\hline EDP ENERGIAS BR & & & & & & & & & $x$ & \\
\hline EMAE & $x$ & & $x$ & & $x$ & & $x$ & & $x$ & \\
\hline \multicolumn{11}{|l|}{ IENERGIA } \\
\hline INVESTCO & & & & & $x$ & & & & $x$ & $x$ \\
\hline \multicolumn{11}{|l|}{ ITAPEBI } \\
\hline LIGHT S/A & & & & & & & $x$ & $x$ & & \\
\hline \multicolumn{11}{|l|}{ TERMOPE } \\
\hline TRACTEBEL & $x$ & $x$ & $x$ & $x$ & & & & $x$ & $x$ & $x$ \\
\hline \multicolumn{11}{|c|}{ Atividade geração - distribuição } \\
\hline CELESC & $x$ & & $\mathrm{x}$ & $x$ & $x$ & $x$ & $x$ & $x$ & $x$ & $x$ \\
\hline CELPA & $x$ & & $x$ & & $x$ & & $x$ & $x$ & $x$ & $x$ \\
\hline CELPE & & & & & & & & & $x$ & $x$ \\
\hline \multicolumn{11}{|c|}{ Atividade geração - transmissão } \\
\hline \multicolumn{11}{|l|}{ AFLUENTE } \\
\hline CEMIG GT & & & & & & & & & $x$ & $x$ \\
\hline \multicolumn{11}{|l|}{ Atividade transmissão } \\
\hline CESP & $x$ & & $x$ & & $x$ & & $x$ & & $x$ & \\
\hline TRAN PAULIST & $x$ & $x$ & $x$ & $x$ & $\mathrm{x}$ & $\mathrm{x}$ & $x$ & $x$ & $x$ & $\mathrm{x}$ \\
\hline Atividade comercializ & & & & & & & & & & \\
\hline
\end{tabular}


Quadro 1 - Demonstrativo das empresas que praticam alguma forma de remuneração estratégica

(continua)

\begin{tabular}{|c|c|c|c|c|c|c|c|c|c|c|}
\hline \multirow[t]{3}{*}{ Empresa } & \multicolumn{10}{|c|}{ Remuneração estratégica } \\
\hline & \multicolumn{2}{|c|}{2003} & \multicolumn{2}{|c|}{2004} & \multicolumn{2}{|c|}{2005} & \multicolumn{2}{|c|}{2006} & \multicolumn{2}{|c|}{2007} \\
\hline & $\mathrm{SI}^{*}$ & $R V^{* *}$ & $\mathrm{SI}^{*}$ & $\mathrm{RV}^{* *}$ & $\mathrm{SI}^{*}$ & $R V^{* *}$ & $\mathrm{SI}{ }^{*}$ & $\mathrm{RV}^{* *}$ & $\mathrm{SI}^{*}$ & $R V^{* *}$ \\
\hline ELETROBRÁS & & & $x$ & $x$ & $x$ & $x$ & $x$ & $x$ & $x$ & $x$ \\
\hline CEMIG & $x$ & $x$ & $x$ & $x$ & $x$ & $x$ & $x$ & $x$ & $x$ & $x$ \\
\hline \multicolumn{11}{|c|}{ Atividade distribuição } \\
\hline AES SUL & $x$ & $x$ & $x$ & $x$ & & & $x$ & $\mathrm{x}$ & $\mathrm{x}$ & $x$ \\
\hline AMPLA ENERG & $x$ & & $x$ & $x$ & $x$ & $x$ & $x$ & $x$ & $x$ & \\
\hline EBE & $x$ & $x$ & $x$ & $x$ & $x$ & $x$ & $x$ & $x$ & $x$ & $x$ \\
\hline \multicolumn{11}{|l|}{ CELG D } \\
\hline CEMIG DIST & & & & & $x$ & $x$ & $x$ & $x$ & $x$ & $x$ \\
\hline CEMAT & $x$ & & & & $x$ & & $x$ & $x$ & $x$ & $x$ \\
\hline COELBA & $x$ & $x$ & & & & & & & & \\
\hline COELCE & $x$ & $x$ & $x$ & $x$ & $x$ & $x$ & $x$ & $x$ & $x$ & $x$ \\
\hline \multicolumn{11}{|l|}{ COSERN } \\
\hline COPEL & $x$ & $x$ & $x$ & $x$ & $x$ & $x$ & $x$ & $x$ & $x$ & $x$ \\
\hline PAUL F LUZ & $x$ & $x$ & $x$ & $x$ & $x$ & $x$ & $x$ & $x$ & $x$ & $x$ \\
\hline CPFL PIRATIN & $x$ & $x$ & $x$ & $x$ & $x$ & $x$ & $x$ & $x$ & $x$ & $x$ \\
\hline ELEKTRO & $x$ & $x$ & $x$ & $x$ & $x$ & $x$ & $x$ & $x$ & $x$ & $x$ \\
\hline ELETROPAULO & & & & & & & $x$ & $x$ & $x$ & $x$ \\
\hline ENERSUL & $x$ & $x$ & $x$ & $x$ & $x$ & $x$ & $x$ & $x$ & $x$ & $x$ \\
\hline ESCELSA & & & $x$ & $x$ & $x$ & $x$ & & & $x$ & $x$ \\
\hline LIGHT & $x$ & $x$ & $x$ & $x$ & $x$ & $x$ & $x$ & $x$ & & \\
\hline RGE & & & $x$ & $x$ & $x$ & $x$ & $x$ & $x$ & $x$ & $x$ \\
\hline \multicolumn{11}{|c|}{ Atividade holding } \\
\hline \multicolumn{11}{|l|}{ BRASILIANA } \\
\hline CEB & $x$ & & & & $\mathrm{x}$ & & & & & \\
\hline CPFL ENERGIA & & & $x$ & $x$ & $x$ & $x$ & $x$ & $x$ & $x$ & $x$ \\
\hline EQUATORIAL & & & & & & & & & $x$ & $x$ \\
\hline \multicolumn{11}{|l|}{ MPX ENERGIA } \\
\hline REDE ENERGIA & $x$ & & $x$ & & $x$ & & $x$ & $x$ & $x$ & $x$ \\
\hline TERNA PART & & & & & & & & & $x$ & $x$ \\
\hline \multicolumn{11}{|c|}{ Atividade particip. em outras sociedades } \\
\hline \multicolumn{11}{|l|}{ AES ELPA } \\
\hline \multicolumn{11}{|l|}{ AMPLA INVEST } \\
\hline \multicolumn{11}{|l|}{ GOIASPAR } \\
\hline ENERGISA & & & & & & & & & $\mathrm{x}$ & $\mathrm{x}$ \\
\hline
\end{tabular}


Quadro 1 - Demonstrativo das empresas que praticam alguma forma de remuneração estratégica

(conclusão)

\begin{tabular}{|c|c|c|c|c|c|c|c|c|c|c|}
\hline \multirow[t]{3}{*}{ Empresa } & \multicolumn{10}{|c|}{ Remuneração estratégica } \\
\hline & \multicolumn{2}{|c|}{2003} & \multicolumn{2}{|c|}{2004} & \multicolumn{2}{|c|}{2005} & \multicolumn{2}{|c|}{2006} & \multicolumn{2}{|c|}{2007} \\
\hline & $S I^{*}$ & $\mathrm{RV}^{* *}$ & $\mathrm{SI}{ }^{*}$ & $\mathrm{RV}^{* *}$ & $\mathrm{SI}^{*}$ & $\mathrm{RV}^{* *}$ & $\mathrm{SI}^{*}$ & $\mathrm{RV}^{* *}$ & $S I^{*}$ & $\mathrm{RV}^{* *}$ \\
\hline \multicolumn{11}{|l|}{ LIGHTPAR } \\
\hline \multicolumn{11}{|l|}{ VBC ENERGIA } \\
\hline Total & 23 & 16 & 25 & 21 & 27 & 20 & 27 & 26 & 34 & 30 \\
\hline Total (SI e ou RV) & \multicolumn{2}{|c|}{24} & \multicolumn{2}{|c|}{25} & \multicolumn{2}{|c|}{27} & \multicolumn{2}{|c|}{28} & \multicolumn{2}{|c|}{34} \\
\hline $\begin{array}{l}\text { Percentual (SI e ou RV) / } \\
\text { total de empresas }\end{array}$ & \multicolumn{2}{|c|}{$46,1 \%$} & \multicolumn{2}{|c|}{$48,0 \%$} & \multicolumn{2}{|c|}{$51,9 \%$} & \multicolumn{2}{|c|}{$53,8 \%$} & \multicolumn{2}{|c|}{$65,4 \%$} \\
\hline
\end{tabular}

Legenda: * SI - salário indireto (benefícios); ** RV - remuneração variável (participação nos lucros e ou resultados); total de empresas: 52. Fonte: Dados da pesquisa.

Na Tabela 1, demonstra-se a evolução de formas de remuneração estratégica adotadas pelas empresas do setor elétrico brasileiro durante o período estudado.

Na Tabela 1, demonstra-se de forma objetiva a evolução na evidenciação da remuneração estratégica, ou seja, apresenta a destinação de recursos sob a forma de salário indireto e ou remuneração variável ao longo do período a que se aplica esta pesquisa. Observa-se que ocorre aumento na evidenciação da remuneração estratégica, ao longo do tempo, tanto que em 2003 o número de empresas que evidenciaram alguma forma de benefícios e participações nos lucros e ou resultados representava $46 \%$ do total, e em 2007 passou para 65\%. Logo, o período entre 2003 e 2007 apresenta um crescimento de $42 \%$ no número de empresas que passam a evidenciar algum benefício ou forma de participação aos seus colaboradores.

Quanto à remuneração variável demonstrada nos relatórios da administração, identifica-se aumento de 31\% para 58\%, na comparação dos anos de 2003 e 2007, respectivamente. Ou seja, as empresas do setor elétrico aumentaram, de forma gradativa, a evidenciação na destinação de participação nos lucros e ou resultados.

O salário indireto compreende os benefícios concedidos pela empresa aos colaboradores. Neste contexto, explicita-se os benefícios disponibilizados, dentre os mais citados, tem-se: alimentação; assistência médica hospitalar e odontológica; educação; transporte; capacitação e desenvolvimento profissional; creches; previdência privada e outros benefícios. Pois, de alguma forma, as empresas destinam recursos na condição de benefícios, independentemente de evidenciarem ou não em seus relatórios da administração.

Por meio da Tabela 2, explicita-se a amostra da pesquisa, com a respectiva representatividade percentual da evidenciação de salário indireto por atividade e por ano.

Observando-se a Tabela 2, constata-se o aumento no número de entidades que passaram a evidenciar salários indiretos entre 2003 e 2007. Destaca-se a atividade de transmissão, no período de 2003 a 2007, na qual $100 \%$ das empresas divulgaram a destinação de recursos sob a forma de salários indiretos. 0 mesmo ocorre na atividade de comercialização para os períodos de 2004 até 2007 . Na atividade de geração e distribuição, constatou-se percentual constante em $66,7 \%$ entre 2003 e 2006 , e em 2007 o percentual de $100 \%$ das empresas que divulgam salários indiretos em seus demonstrativos contábeis.

Por intermédio da Tabela 3, visualiza-se a amostra da pesquisa e a perspectiva de evidenciação de remuneração variável por atividade e por ano.

A partir da base de informações presentes na Tabela 3, constata-se o aumento no percentual de empresas que divulgam remuneração variável aos colaboradores, no período de 2003 a 2007. Neste contexto, considera-se a remuneração variável como um incentivo ao colaborador no sentido dele vir a se comprometer com os objetivos organizacionais, fato que pode contribuir de forma positiva na competitividade da empresa. Quanto ao colaborador, acredita-se 
Tabela 1 - Remuneração estratégica por percentual e por período (SI e RV)

\begin{tabular}{|c|c|c|c|c|c|c|c|c|c|c|}
\hline & 2003 & $\%$ & 2004 & $\%$ & 2005 & $\%$ & 2006 & $\%$ & 2007 & $\%$ \\
\hline Possui SI & 23 & 44 & 25 & 48 & 27 & 52 & 27 & 52 & 34 & 65 \\
\hline Possui RV & 16 & 31 & 21 & 40 & 20 & 38 & 26 & 50 & 30 & 58 \\
\hline Possui SI e ou RV & 24 & 46 & 25 & 48 & 27 & 52 & 28 & 54 & 34 & 65 \\
\hline Não possui SI e nem RV & 28 & 54 & 27 & 52 & 25 & 48 & 24 & 46 & 18 & 35 \\
\hline
\end{tabular}

Lengenda: * SI - salário indireto (benefícios); ** RV - remuneração variável (participação nos lucros e ou resultados).

Fonte: Dados da pesquisa.

Tabela 2 - Percentual de salário indireto por atividade

\begin{tabular}{|c|c|c|c|c|c|c|c|c|c|c|c|}
\hline Atividades & Empresas & 2003 & $\%$ & 2004 & $\%$ & 2005 & $\%$ & 2006 & $\%$ & 2007 & $\%$ \\
\hline Geração & 12 & 4 & 33,3 & 5 & 41,7 & 5 & 41,7 & 5 & 41,7 & 7 & 58,3 \\
\hline Geração e distribuiç̧ão & 3 & 2 & 66,7 & 2 & 66,7 & 2 & 66,7 & 2 & 66,7 & 3 & 100,0 \\
\hline $\begin{array}{l}\text { Geração e transmis- } \\
\text { são }\end{array}$ & 2 & 0 & 0,0 & 0 & 0,0 & 0 & 0,0 & 0 & 0,0 & 1 & 50,0 \\
\hline Transmissão & 2 & 2 & 100,0 & 2 & 100,0 & 2 & 100,0 & 2 & 100,0 & 2 & 100,0 \\
\hline Comercialização & 2 & 1 & 50,0 & 2 & 100,0 & 2 & 100,0 & 2 & 100,0 & 2 & 100,0 \\
\hline Distribuição & 18 & 12 & 66,7 & 12 & 66,7 & 13 & 72,2 & 14 & 77,8 & 14 & 77,8 \\
\hline Holding & 7 & 2 & 28,6 & 2 & 28,6 & 3 & 42,9 & 2 & 28,6 & 4 & 57,1 \\
\hline $\begin{array}{l}\text { Partic. outras socie- } \\
\text { dades }\end{array}$ & 6 & 0 & 0,0 & 0 & 0,0 & 0 & 0,0 & 0 & 0,0 & 1 & 16,7 \\
\hline Total & 52 & 23 & 44,2 & 25 & 48,1 & 27 & 51,9 & 27 & 51,9 & 34 & 65,4 \\
\hline
\end{tabular}

Fonte: Dados da pesquisa.

Tabela 3 - Percentual de remuneração variável por atividade

(continua)

\begin{tabular}{|c|c|c|c|c|c|c|c|c|c|c|c|}
\hline Atividades & Empresas & 2003 & $\%$ & 2004 & $\%$ & 2005 & $\%$ & 2006 & $\%$ & 2007 & $\%$ \\
\hline Geração & 12 & 4 & 33,3 & 4 & 33,3 & 3 & 25,0 & 5 & 41,7 & 5 & 41,7 \\
\hline $\begin{array}{l}\text { Geração e dis- } \\
\text { tribuição }\end{array}$ & 3 & 0 & 0,0 & 1 & 33,3 & 1 & 33,3 & 2 & 66,7 & 3 & 100,0 \\
\hline $\begin{array}{l}\text { Geração e transmis- } \\
\text { são }\end{array}$ & 2 & 0 & 0,0 & 0 & 0,0 & 0 & 0,0 & 0 & 0,0 & 1 & 50,0 \\
\hline Transmissão & 2 & 1 & 50,0 & 1 & 50,0 & 1 & 50,0 & 1 & 50,0 & 1 & 50,0 \\
\hline Comercialização & 2 & 1 & 50,0 & 2 & 100,0 & 2 & 100,0 & 2 & 100,0 & 2 & 100,0 \\
\hline Distribuição & 18 & 10 & 55,6 & 12 & 66,7 & 12 & 66,7 & 14 & 77,8 & 13 & 72,2 \\
\hline
\end{tabular}


CARDOZO, R. de M.; NASCIMENTO, C. do; GASPARETTO, V.

Tabela 3 - Percentual de remuneração variável por atividade

\begin{tabular}{lcccccccccccc} 
(conclusão) \\
\hline \multicolumn{1}{c}{ Atividades } & Empresas & $\mathbf{2 0 0 3}$ & $\%$ & $\mathbf{2 0 0 4}$ & $\%$ & $\mathbf{2 0 0 5}$ & $\%$ & $\mathbf{2 0 0 6}$ & $\%$ & $\mathbf{2 0 0 7}$ & $\%$ \\
\hline $\begin{array}{l}\text { Holding } \\
\begin{array}{l}\text { Partic. outras socie- } \\
\text { dades }\end{array}\end{array}$ & 7 & 0 & 0,0 & 1 & 14,3 & 1 & 14,3 & 2 & 28,6 & 4 & 57,1 \\
Total & 5 & 0 & 0,0 & 0 & 0,0 & 0 & 0,0 & 0 & 0,0 & 1 & 16,7 \\
\hline
\end{tabular}

Fonte: Dados da pesquisa.

que, com a expectativa de receber um valor além da sua remuneração normal, pode afetar de forma significativa a sua vida, no sentido de se permitir a planejar o uso deste dinheiro. Desse modo, ele tende a procurar desempenhar suas atividades para que a empresa tenha lucro.

Identificou-se a divulgação de duas modalidades de remuneração estratégica, sendo salários indiretos que correspondem a benefícios, e remuneração variável que corresponde à participação nos lucros e ou resultados. No estudo sobre a evidenciação de salário indireto, optou-se pela diferenciação por atividade em que as empresas atuam. Com isto, observou-se que é na atividade distribuição em que se encontra o maior número de empresas que destacam a remuneração por salário indireto. A adesão na destinação de recursos para salários indiretos foi crescente em número de empresas e em todas as atividades com evidenciação de salários indiretos em 2007 comparativamente a 2003. Este estudo constata crescimento no número de empresas que passaram a divulgar remuneração variável nos relatórios da administração, de 16 para 30, no período de 2003 a 2007, respectivamente.

Dada a relevância do tema evidenciação da remuneração estratégica em empresas do setor elétrico brasileiro, como forma de estímulo ao bom desempenho dos colaboradores, ressalta-se a possibilidade das empresas, em última análise, também serem beneficiadas, direta e indiretamente, por disporem de colaboradores mais comprometidos com a entidade.

\section{Considerações finais}

A pesquisa teve como objetivo principal identificar as informações sobre as formas de remuneração estratégica evidenciadas nos relatórios da administração das empresas brasileiras de energia elétrica com ações negociadas na BM\&FBOVESPA. Para isso, a problemática da pesquisa foi resumida na seguinte questão-problema: quais as formas de remuneração estratégica adotadas pelas empresas brasileiras de energia elétrica que têm ações negociadas na BM\&FBOVESPA? A resposta foi alcançada a partir da análise dos dados, organizados em quadro e tabelas. Salienta-se que as referidas empresas evidenciam remuneração estratégica sob a forma de salários indiretos e remuneração variável.

Constatou-se a evolução significativa do número de empresas que passaram a evidenciar as formas de remuneração estratégica. Quanto ao salário indireto evidenciado por atividade, destacam-se as atividades de geração e distribuição, transmissão, e comercialização com expressivo percentual na divulgação de tais informações. Nas atividades de geração e distribuição, e também na de comercialização, existe expressiva representatividade no percentual de empresas que evidenciaram remuneração variável. Destaca-se que 11 empresas com representatividade de $21 \%$ evidenciaram, simultaneamente, no relatório da administração, a destinação de remuneração variável e salário indireto, ao longo de todo o período pesquisado. Salienta-se que $15,4 \%$ das empresas utilizaram-se da remuneração estratégica em apenas um período.

Por fim, o presente estudo, mediante levantamento de dados e informações contidas nos relatórios da administração, possibilitou constatar que 73\% da amostra evidenciou remuneração estratégica no período transcorrido de 2003 até 2007. Porém, ressalta-se a existência de empresas que ainda não visualizaram a importância da divulgação das práticas referentes às formas de remuneração do colaborador. Essa informação tem relevância à medida que considera-se que a remuneração estratégica representa a atenção dada pela empresa em relação ao desempenho e satisfação de seus colaboradores. 


\section{Referências}

BM\&FBOVESPA - Bolsa de Valores. Mercadorias e Futuros. Disponível em: <http://www.bovespa.com.br/ Principal.asp>. Acesso em: 9 abr. 2008.

CARDOSO, L. R. A participação nos lucros como componente de um sistema de remuneração estratégica: um estudo de caso. In: SEMINÁRIO DE ADMINISTRAÇÃO. 4., 1999, São Paulo. Anais... São Paulo: SEMEAD, 1999. Disponível em: <http://www.ead.fea.usp.br/semead/artigos/rh/cardoso. pdf>. Acesso: 14 maio 2008.

CERVO, A. L.; BERVIAN, P. A.; SILVA, R. Metodologia científica. 6. ed. São Paulo: Pearson Prentice Hall, 2007.

CHIAVENATO, I. Gestão de pessoas: e o novo papel dos recursos humanos nas organizações. 2. ed. Rio de Janeiro: Elsevier, 2004.

CLASEN, E. Um estudo sobre o estabelecimento de metas e sua aferição nos programas de remuneração variável em companhias de capital aberto de Joinville SC. 2000. 158 f. Dissertação (Mestrado em Administração) Universidade Federal de Santa Catarina, Florianópolis, 2000 .

FIGUEIREDO, S.; CAGGIANO, P. C. Controladoria: teoria e prática. 2. ed. São Paulo: Atlas, 1997.

HENDRIKSEN, E. S.; VAN BREDA, M. F. Teoria da contabilidade. São Paulo: Atlas, 1999.

HIPÓLITO, J. A. M. Remuneração por competências: recompensando o desenvolvimento e a contribuição do profissional. FAE BUSINESS, n. 3, p. 28-31, 2002.

IUDÍCIBUS, S. Contabilidade gerencial. 6. ed. São Paulo: Atlas, 1998.

IUDÍCIBUS, S. Teoria da contabilidade. 7. ed. São Paulo: Atlas, 2004.
IUDÍCIBUS, S.; MARION, J. C. Introdução à teoria da contabilidade para o nível de graduação. São Paulo: Atlas, 1999.

IUDÍCIBUS, S.; MARTINS, E.; GELBCKE, E. R. Manual de contabilidade das sociedades por ações. 6. ed. São Paulo: Atlas, 2007.

LUNKES, R. J. Contabilidade gerencial: um enfoque na tomada de decisão. Florianópolis: VisualBooks, 2007.

MIRANDA, C. A importância da remuneração estratégica. Rede Gestão, 2005. Disponível em: <http://desafio21.informazione2.com.br>. Acesso em: 3 abr. 2008.

RAUPP, F. M.; BEUREN, I. M. Metodologia da pesquisa aplicável às Ciências Sociais. In: BEUREN, I. M. (Org.). Como elaborar trabalhos monográficos em contabilidade: teoria e prática. São Paulo: Atlas, 2006. p. 76-97.

REIS NETO, M. T.; MARQUES, A. L. A remuneração variável e sua contribuição para melhoria da gestão. Revista de Negócios, v. 9, n. 1, p. 5-18, 2004.

RICHARDSON, R. J. Pesquisa social: métodos e técnicas. 3. ed. São Paulo: Atlas, 1999.

TRIVIÑOS, A. N. S. Introdução à pesquisa em ciências sociais: a pesquisa qualitativa em educação. São Paulo: Atlas, 2006.

WOOD JUNIOR, T.; PICARELLI FILHO, V. Remuneração estratégica: a nova vantagem competitiva. São Paulo: Atlas, 1996.

Recebido: 20/09/2011

Received: 09/20/2011

Aprovado: 18/10/2011

Approved: 10/18/2011 